\title{
Redes Sociais: um jornal on-line como fonte de informação especializada em turismo
}

\author{
Social Network: an online newspaper as a source of \\ specialized information on tourism
}

\section{Redes Sociales: Un periódico online como fuente de información especializada en el turismo}

\author{
Antônio Claret Guerra ${ }^{1}$ \\ Marlusa Gosling ${ }^{2}$ \\ Mariana de Freitas Coelho ${ }^{3}$
}

Resumo: Este artigo busca fornecer subsídios para uma avaliação objetiva da importância das redes sociais baseadas na internet, como fonte de informação em turismo. $O$ foco são pesquisas qualitativas feitas pela Associação Nacional de Jornais (ANJ), auditorias do Instituto Verificador de Circulação (IVC), entrevistas com jornalistas e especialista em mídia digital, e consultas realizadas no portal O Tempo. O método escolhido foi uma abordagem qualitativa e exploratória, através de estudo de caso. A coleta de dados envolveu um levantamento de dados documentais e entrevistas direcionadas. Em termos de resultados, constatou-se que o uso das redes sociais foi feito por públicos estimados de 8,8 milhões a 10,7 milhões de pessoas, apenas na empresa jornalística pesquisada, no ano de 2011. Identificou-se, ainda, que a ampliação exponencial de possibilidades de contatos diretos com públicos diversos, nos ambientes das redes sociais, induz à aproximação e fidelização do leitor e o jornalista e, ao mesmo tempo, facilita o acesso à informação, o que possibilita o desenvolvimento de veículos de comunicação específicos para esses novos meios.

Palavras-chave: Rede Social; Turismo; Jornalismo especializado na internet.

Abstract: This paper aims providing information for an objective assessment of the importance of social networks based on the internet as a source of information on tourism. The study was sustained with qualitative researches from the the Brazilian National Newspaper Association (ANJ), audits of the Circulation Verification Institute (IVC), interviews with journalists and an expert in digital media, and enquiries at "O Tempo" website. The chosen method was qualitative and exploratory, using a case study approach. The data collection comprehended documentary research and targeted interviews. Among the results, in the researched company it was identified the use of social networks by esteemed public of 8.8

1 Jornalista e Mestre em Administração, com ênfase em mídias sociais e turismo Diretor-Geral do JORNAL MG TURISMO e Diretor Nacional da Abrajet. E-mail: claret.mgturismo@uol.com.br

2 Doutora em Administração. Professora Associada da Universidade Federal de Minas Gerais (UFMG). E-mail: mg.ufmg@gmail.com

3 Doutoranda em Administração pelo Cepead/ UFMG. Mestre em Administração - UFMG. Bacharel em Turismo UFMG. E-mail: marifcoelho@gmail.com 
million to 10.7 million people in the year of 2011. Also, the study recognized the exponential expansion of possibilities for direct contact with diverse audiences in the social networks environments, inducing the approximation and loyalty of the reader and the journalist. Also, social networks facilitate access to information, which enables the development of specific communication vehicles to these new media.

Keywords: Social Networks; Tourism; Internet Journalism.

Resumen: En este artículo busca proporcionar información para una evaluación objetiva de la importancia de las redes sociales basadas en Internet como fuente de información para el turismo. El estudio se sustenta en las investigaciones cualitativas de la Asociación Nacional de Periódicos de Brasil (ANJ), auditorías del Instituto de Verificación de Circulación (IVC), entrevistas con periodistas y un experto en medios digitales y consultas en la página web del periódico brasileño "O Tempo". El método elegido fue cualitativo y exploratorio, utilizando un enfoque de estudio de caso.La recogida de datos comprendió la investigación documental y entrevistas focalizadas. Entre los resultados, en la empresa investigada se identificó el uso de las redes sociales por el público estimado de 8,8 millones a 10,7 millones de personas en el año de 2011. Asimismo, el estudio reconoció la expansión exponencial de posibilidades para el contacto directo con el público en los diversos ambientes de redes sociales, que induce a la aproximación y la lealtad del lector y el periodista. Además, las redes sociales facilitan el acceso a la información, lo que permite el desarrollo de vehículos de comunicación específicas para estos nuevos medios.

Palabras clave: Redes Sociales; Turismo; Periodismo especializado en internet.

\section{INTRODUÇÃO}

Com 5,8 milhões de visitantes estrangeiros em 2011, segundo o Instituto Brasileiro de Turismo (EMBRATUR), o Brasil é o principal destino do mercado turístico internacional na América do Sul, e ocupa o segundo lugar na América Latina, em termos de fluxo de turistas internacionais. (EMBRATUR, 2011).

A internet é uma criação muito recente na história da humanidade, não sendo ainda plenamente conhecidas suas potencialidades e suas consequências sobre a vida social, profissional e mesmo biológica dos seres humanos, apesar das profundas mudanças que ocasiona nas relações sociais. Lopes (2007) vê as consequências do uso de sites de relacionamento, conhecidos como redes sociais on-line, para as relações de amizade e para as noções de identidade, privacidade, autenticidade, comunidade e sociabilidade como apenas despontando.

Outro estudo, feito pela Google sobre o consumidor brasileiro de turismo na internet e divulgado pela agência EMarket (2009), mostrou que $89 \%$ dos internautas entrevistados utilizam pelo menos uma fonte on-line para comprar algum tipo de produto relacionado a turismo, como reserva de hotel, passagens aéreas, aluguel de carros e viagens em cruzeiros. Logo, as múltiplas fontes de informação sobre os destinos turísticos no ambiente on-line são importantes para o planejamento de viagem e escolha do destino turístico (Mattila, 2004). Contudo, Pan e Fesenmaier (2006) indicam uma carência de estudos sobre informações turísticas on-line para o planejamento de viagens, principalmente no nível micro.

Assim, a questão da informação e do conhecimento de empresas jornalísticas editoras de 
cadernos turismo, os quais são disponibilizados nas redes sociais baseadas na internet, merecem maior investigação.

O avanço tecnológico, associado à democratização dos meios de circulação e acesso às informações, coloca empresas e públicos consumidores em posição às vezes distante. No entanto, à medida que essa proximidade se intensifica pelos benefícios do mundo moderno, o planejamento e o relacionamento figuram como partes essenciais da comunicação, sendo que, para essa prática efetiva, são indispensáveis identificar os públicos alvo e a melhor forma de conduzir o relacionamento com cada um deles.

Segundo Zauner et al.(2012), uma grande parte da população está conectada ou pelo menos informada sobre a mídia social. O conceito de mídia social proposto por Ruzic e Bilos (2010) é de aplicativos/serviços gratuitos da internet que fornecem um ou mais canais de comunicação com seus usuários para comunicação com outros usuários, na forma de autoapresentação e criação de público (seguidores) ou de comunicação interativa com amigos.

Miguéns et al. (2008) define redes sociais como comunidades on-line as quais indivíduos compartilham interesses e atividades. Deste modo, as redes sociais são um instrumento de mídia social os quais podem ser utilizados por consumidores e organizações turísticas. De outra forma, as redes sociais podem ser consideradas em um sentido mais amplo, no qual são fundamentais na estrutura da sociedade (Tuten; Solomon, 2013). Uma das características mais importantes deste tipo de rede é justamente a sua natureza social, o que as conecta umbilicalmente ao conceito de relacionamento social, situação na qual duas ou mais pessoas estão engajadas em conduzir uma ação onde cada um considera o comportamento do outro de uma maneira significativa.

As redes sociais baseadas na internet, como fonte de informação para a decisão de viajar, oferecem a possibilidade de leitores, clientes e parceiros terem ferramentas digitais e recursos tecnológicos que ampliem seus horizontes, oportunidades e possibilidades. No que diz respeito ao seu uso para a obtenção de informação e conhecimento para a decisão de viajar, trata-se também de um fenômeno bastante recente, e, consequentemente, pouco estudado.

No setor empresarial, a mídia social vem para auxiliar o jornalismo. Essa é a tese defendida por Arianna Huffington, do site Huffington Post (EUA), em entrevista à Folha de S. Paulo, edição de 3 de setembro de 2011 (Dias, 2011). Segundo ela, não há, por princípio, uma separação estanque com os chamados veículos tradicionais:

Há algo que falta na mídia tradicional que nós podemos capturar nas mídias sociais: contar histórias. Estamos preocupados demais com dados. É muito mais difícil capturar leitores com dados do que com histórias. O Huffington Post é um exemplo de como aproveitar o melhor as mídias sociais. Nós não damos apenas informações ao leitor. Damos uma plataforma onde ele pode compartilhar seus pontos de vista e seus hobbies. Disse ainda que é preciso entender melhor como essa mudança altera o uso da informação. Antes consumíamos as noticias no sofá. Agora fazemos isso galopando. As mídias sociais revolucionaram também a maneira como as empresas se relacionaram com os consumidores. Não pense no Twitter como um mapa da vida das pessoas, mas sim como um mapa da mente delas. (Dias, 2011). 
A internet padroniza e dá igualdade de condições para quem deseja trocar conhecimento e se comunicar. A internet é um instrumento sem precedentes para a criação de novos modelos de negócios, possibilitando a formação de novas empresas, novas formas de trabalhar e de atuar na sociedade.

Tendo em vista esse cenário, foi realizada uma pesquisa buscando obter resposta para a seguinte indagação: Como as redes sociais baseadas na internet podem ser usadas como canal de informação para o turista, na visão de uma empresa jornalística editora de caderno de turismo?

A pesquisa teve o objetivo de investigar o uso das redes sociais baseadas na internet como fonte de informação para o conhecimento de destinos turísticos no Brasil e no exterior, sob a ótica de uma empresa jornalística, o jornal 'O Tempo'. Assim, buscou-se identificar a utilização das redes sociais de um jornal específico na disseminação da informação jornalística especializada em turismo e levantar os efeitos dessa utilização, sempre na ótica dos produtores da informação.

A pesquisa justifica-se pelo fato de que a utilização das redes sociais é crescente em todo o mundo e pode se tornar uma vantagem competitiva por parte das empresas jornalísticas, inclusive na difusão do conhecimento especializado em turismo.

\section{REFERENCIAL TEÓRICO}

Uma pesquisa necessita ancorar-se em estudos já realizados sobre o tema escolhido. Assim, foi elaborado aqui um Referencial Teórico enfocando os seguintes pontos: redes sociais baseadas na internet, informação turística e as redes sociais baseadas na internet e a informação turística.

\subsection{Redes Sociais baseadas na internet}

A mídia social é um canal de marketing, as redes sociais se transformam em diferencial competitivo para as empresas, a interatividade e a expansão geométrica demonstram que as redes sociais são formas de sociabilidade e de socialização da informação e do conhecimento. Assim, as limitações de tempo e de espaço se minimizam, permitindo trocas entre os membros dos círculos sem que eles se vejam pessoalmente (Afonso, 2010).

A relação entre redes sociais é associada a mudanças que vêm ocorrendo a partir do uso da Internet comercial. Porém, as redes sociais são formas de sociabilidade e de socialização de informação e conhecimento que começaram a ser estudadas há mais de 75 anos, quando as tecnologias de informação e comunicação (TICS) ainda não haviam assumido papel significativo na intermediação das relações interpessoais e sociais (Lopes, 2007). Para Tuten e Solomon (2013), em linhas gerais, a mídia social se refere aos meios de comunicação que permite a interação entre as pessoas, podendo ela ser promovida on-line ou não. Portanto, redes e mídias sociais já existiam antes da internet, mas passam a ser propagadas com maior velocidade com auxílio da difusão e 
acesso à internet.

De outra forma, Tótoli e Rossi (2012) estabelecem que a mídia social é possibilitada apenas pela conexão pela internet. "A mídia social se define pela geração e troca de conteúdo por um grupo de pessoas com base em suas conexões pela internet" (Tótoli; Rossi, 2012, P. 2). Assim, neste trabalho, as redes sociais organizadas usando a infraestrutura de comunicação oferecida pela Internet serão denominadas redes sociais baseadas na Internet.

De acordo com Berthier Ribeiro Neto, diretor da Google para a América Latina, as redes sociais baseadas na Internet replicam os círculos tradicionais de amizade, mas os amplificam, porque as limitações de tempo e espaço deixam de existir, permitindo trocas entre os membros desses círculos sem que eles se vejam pessoalmente (Afonso, 2010). Ainda segundo o autor, por causa dessas características, o sucesso dessas redes entre os usuários da Internet foi vertiginoso. Apenas três dos mais conhecidos exemplos de redes desse tipo, o Orkut (85 milhões de usuários, dos quais 43 milhões são no Brasil), o Facebook (mais de 600 milhões de usuários ativos) e o Twitter (200 milhões de usuários), beiram os 900 milhões de usuários espalhados pelo mundo.

No que diz respeito especificamente ao uso das redes sociais baseadas na Internet pelos brasileiros, a pesquisa TG.Net, realizada pelo IBOPE Mídia em regiões metropolitanas e no interior do Sul e do Sudeste, mostrou que $72 \%$ dos internautas nacionais já incorporaram às suas rotinas o hábito de navegar em sites de redes sociais, sobretudo para interagir com amigos, atualizar perfis e compartilhar fotos, em sites como Orkut, Facebook, Twitter e LinkedIn (IBOPE, 2011).

\subsection{Informação turística}

Turismo e Comunicação formam um conjunto indissociável (Rushmann, 1990), já que as viagens turísticas são realizadas cada vez mais, no mundo globalizado, em razão do acesso a informações transmitidas pelos "mass midia" (meios de comunicação de massa) tradicionais - o jornal, o rádio, a televisão.

A era pré-internet forçava o uso de intermediários, como agentes de viagens e operadores turísticos, para distribuir os produtos e serviços turísticos (Buhalis; Law, 2008). Contudo, com a internet, gestores de destinos turísticos e empresas cada vez mais necessitam encontrar métodos inovadores para garantir sua competitividade (Buhalis, 1998).

Para Ruschmann e Quadro (2008), é inegável o papel exercido pelos meios de comunicação na efetivação das viagens turísticas, já que o turista necessita conhecer detalhes dos produtos e destinos que deseja visitar. Estudos de Recepção, que se desenvolveram no âmbito da Comunicação Social, realizados por Ronsini (1993), tiveram como principal hipótese a de que as informações contidas em reportagens sobre destinos turísticos influenciam decisivamente nas escolhas que os turistas fazem por uma ou outra destinação.

Saber das necessidades do turista é o ponto inicial para estabelecer a necessária comunicação. Como todos os bens ou serviços, a viagem turística é precedida de uma necessidade específica, a qual gera um motivo para os deslocamentos e estabelece um objetivo para a viagem 
a se realizar, (Anderson; Langmeyer, 1982).

A busca de informação turística é vista como resultado de um processo dinâmico, no qual os viajantes usam vários tipos e quantidades de fontes para responder às contingências internas e externas referentes ao planejamento de viagens. Buhalis e Law (2008) destacam a importância da internet como canal que potencializa a distribuição da informação sobre organizações de destinos turísticos entre consumidores.

Segundo Ye et al.(2009), há aumento no número de viajantes utilizando a internet para planejar suas viagens. Pan e Fesenmaier (2006) acrescentam que a internet é um dos meios mais efetivos para turistas buscarem informações e comprarem produtos turísticos. Ainda, o empoderamento dos viajantes ao planejarem suas viagens tem estimulado a reserva e compra de produtos e serviços turísticos através de websites (Tierney, 2000).

Em uma perspectiva mais holística, todos os meios de comunicação podem ser utilizados numa campanha de comunicação voltada para o mercado turístico. Assim, a comunicação de massa, pela televisão e pela internet, desempenha um papel crucial nesse processo, representando uma fonte de informação cujo uso torna-se cada vez mais freqüente na oferta de produtos turísticos (Kliatchko, 2002; Nielsen, 2002).

\subsection{As redes sociais baseadas na internet e a informação turística}

Um dos pontos a serem analisados, quando se fala em informação, diz respeito à necessidade que sentem, certas pessoas, de acessá-la como consumidores e cidadãos, o que deve ser levado em conta na proposição de serviços públicos que possibilitem tal acesso, de forma livre, igualitária e gratuita (Moore, 1999). Só assim o cidadão comum será beneficiado pelo novo paradigma tecnológico.

O desenvolvimento das tecnologias da informação e comunicação propiciou o surgimento do ciberespaço, "novo espaço de comunicação, de sociabilidade, de organização e de transação, mas também novo mercado da informação e do conhecimento" (Lévy, 1999, p.32).

Para Swarbrooke e Horner (2002), as novas tecnologias de informação e comunicação que vêm reforçando a utilização das mídias tradicionais como o jornal, a revista, televisão e o rádio, por meio de uma estratégia integrada, em tempo real e acessível, de diversas formas em todo o mundo. Os autores lembram que, apesar de as novas mídias serem importantes, os métodos de comunicação tradicionais ainda desempenham papel fundamental, não se devendo descuidar deles, principalmente no que tange à mídia impressa, folhetos, promoção de vendas, vendas pessoais, mala direta e divulgação em pontos de venda (Kliatchko, 2002).

Para Von Huelsen (2008), no que diz respeito à administração de empresas, o interesse pela Internet geralmente está ligado a fatores como relações de negócio e transações, por ser este um ambiente que favorece o compartilhamento de informações, conhecimento de comportamento de consumo e redução de custos. Segundo essa autora, a Internet costuma ser vista como canal de marketing que permite contato direto com consumidores. Para ela, o uso da 
rede pode ir além da difusão de informação e mensagens, podendo promover o estabelecimento de vínculos entre empresas e consumidores. Para o leitor, é uma oportunidade para encontrar uma seleção clara do que mais relevante há para ler neste momento, incluindo relatos dos últimos acontecimentos e textos de análise. Portanto, cientes da ubiquidade da internet, cada vez mais os profissionais têm utilizado os canais de distribuição online como ferramenta de marketing (Tuominen, 2011).

A informação turística, devido especialmente ao fomento promovido pelas entidades da imprensa especializada, como a Associação Brasileira de Jornalistas e Escritores de Turismo (Abrajet), já possui grande expressividade no Brasil. Nessa linha de raciocínio, Erbolato (1981, p.59), ainda na década de 80 , já afirmava que:

O turismo é abordado com destaque, na imprensa brasileira, com bastante ilustrações, a maior parte em cores, mostrando cidades do País ou estrangeiras. As matérias visam incentivar o leitor a viajar e, por isso, abordam temas ilimitados: museus, campismo, roteiros de viagens, preços de hotéis e passagens, excursões promovidas por empresas especializadas, novidades das companhias de aviação (inauguração de rotas, compra de novos aparelhos, substituição de uniformes do pessoal de terra e das aeromoças), centros campestres, hotelaria, pesca, tábua de marés, cardápios de restaurantes, cruzeiros marítimos, comemorações, política do turismo, reformas de aeroportos, automobilismo, como viajar para o exterior (passaporte, vistos, compra de passagens, limite de dólares, o que pode ser trazido, como remeter dinheiro a quem se encontra em outro país) e outros.

Ferrari (2002) adverte, entretanto, que a informação em geral, incluída aquela especializada em turismo, tem papel limitado no processo de divulgação:

O jornalismo não pode ser considerado como uma ferramenta de marketing, porém tem um papel muito importante em um planejamento de comunicação (...) a rigor, não corresponde a uma ação de marketing, visto que seus princípios simplicam a necessidade de autonomia do veículo para a difusão da informação. (Ferrari, 2002, p.75).

Por fim, conforme Xiang e Gretzel (2010), a prática de marketing de turismo atualmente tem dado atenção ao uso de mídia social para criar imagens positivas e comunicação boca-a-boca para destinos e empreendimentos turísticos, o que pode impulsionar o desejo de viagem ao destino por parte dos consumidores.

\section{METODOLOGIA}

A pesquisa realizada se caracteriza como exploratória, ( $\mathrm{Gil}, 2002$ ) por investigar o uso de redes sociais e a difusão da informação e do conhecimento especializados em turismo, temas ainda pouco enfocados pela academia. A abordagem foi qualitativa, que permite o aprofundamento do estudo de um fenômeno.

Quanto aos meios utilizados, utilizou-se um estudo de caso, que, segundo Yin (2005, p.32), "é uma investigação empírica que investiga um fenômeno contemporâneo dentro de seu contexto 
na vida real, especialmente quando os limites, entre o fenômeno e o contexto, não estão claramente definidos". Para o mesmo autor, a documentação é uma fonte de evidências com vários pontos fortes, pelo fato de ser estável e poder ser revisada inúmeras vezes; ser discreta, por não ter sido criada como resultado do estudo de caso; e ser exata, por conter nomes, referências e detalhes exatos do evento. Ainda de acordo com Yin (2005), os dados podem ser obtidos de seis fontes diferentes: documentação, registro em arquivos, entrevistas, observações diretas, observações participantes e artefatos físicos. No caso da pesquisa aqui relatada, foram utilizados documentos e entrevistas semiestruturadas.

Primeiramente, foi realizada uma pesquisa documental, circunscrita aos jornais integrantes da Associação Nacional de Jornais (ANJ), com destaque para a publicação 'O Tempo', editada em Belo Horizonte (MG). Foi também consultada a auditoria do Instituto Verificador de Circulação (IVC), efetuada na audiência web de publicações on-line do referido veículo de comunicação.

O levantamento de dados ocorreu também através da consulta à pesquisa intitulada 'Práticas de Comunicação Digital', realizada pela ANJ, para conhecer as principais práticas, o uso profissional e/ou pessoal, a existência (ou não) de regras, o grau de tolerância, as ocorrências e os comentários sobre as mídias sociais. Os jornais participantes da pesquisa são as 80 publicações integrantes da base de associados da entidade, entre as quais o jornal 'O Tempo', o qual foi escolhido por ser um jornal relevante em Belo Horizonte e Região Metropolitana e também por conveniência para a coleta de dados. O estudo, realizado no período de 21/09 a 10/10/11, apresentou um panorama da utilização das redes sociais nas redações dos principais jornais do país.

Os dados do Instituto Verificador de Circulação (IVC) são referentes à audiência web, sendo o órgão filiado à International Federation of Audit Bureaux of Circulations (IFABC), o que assegura que os processos adotados pela instituição seguem os padrões mundiais de auditoria de mídia.

Foram também realizadas entrevistas, sendo que a escolha dos entrevistados se deu por acessibilidade (Vergara, 2003), tendo em vista a disponibilidade dos mesmos em conceder as entrevistas. Foram feitas três entrevistas, em janeiro de 2012, com a secretária de redação de ' $O$ Tempo', com o antigo editor de turismo dessa publicação, durante o período 2007-2010, e com um especialista em mídias sociais.

A primeira entrevista foi realizada na redação do jornal 'O Tempo', em Contagem, na Região Metropolitana de Belo Horizonte (MG). A segunda foi feita através de e-mail, por dificuldade de conciliação de agendas, e a terceira foi realizada em São Paulo (SP), por ocasião do XVII Workshop e Trade Show CVC, realizado no Expo Center Norte.

A análise de conteúdo (Bardin, 2008), instrumento de análise interpretativa, foi o método empregado para a interpretação dos dados coletados no presente estudo. Assim, a análise considerou dados da pesquisa documental e trechos de entrevistas que se relacionavam à categoria temática da internet como fonte de informação em turismo, com um recorte de redes sociais. Por fim, buscou-se integrar os dados à teoria apresentada no referencial teórico para se alcançar o objetivo proposto pelo artigo. 


\section{ANÁLISE DOS RESULTADOS}

A análise dos dados considerou tanto os dados secundários, coletados durante a pesquisa documental, quanto os dados primários, isto é, as entrevistas com especialistas. Os resultados são apresentados a seguir, buscando interseção com a literatura.

A pesquisa 'Estudo da Demanda Turística Internacional - 2004-2010', divulgada pelo Ministério do Turismo, em janeiro de 2012, demonstra que 32,9\% dos viajantes buscam informações pela internet, sendo a mesma, portanto, a principal fonte de orientação para as viagens turísticas.

O Quadro 1 mostra como o turista se orienta, no Brasil, para decidir o destino de uma viagem nacional e internacional. A utilização da fonte 'amigos e parentes' que, em 2004, era feita por $37,3 \%$ dos entrevistados, diminuiu, em 2010, para 28,4\%, trajetória inversa de 'internet', que, de $26,8 \%$, em 2004, aumentou para 30,9\%, em 2010. Por outro lado, as 'agências de viagens' continuaram a ser utilizadas pelos turistas na organização de suas viagens, sempre por cerca de 10\% dos entrevistados, no período 2004-2010.

Quadro 1 - Fontes de Informação para a Organização de Viagem

\begin{tabular}{|l|l|l|l|l|l|l|l|}
\hline FONTE DE INFORMAÇÃO & $\mathbf{2 0 0 4}$ & $\mathbf{2 0 0 5}$ & $\mathbf{2 0 0 6}$ & $\mathbf{2 0 0 7}$ & $\mathbf{2 0 0 8}$ & $\mathbf{2 0 0 9}$ & $\mathbf{2 0 1 0}$ \\
\hline Internet & 26,8 & 19,9 & 24,4 & 27,6 & 27,5 & 30,1 & 30,9 \\
\hline Amigos e parentes & 37,3 & 43,1 & 39,7 & 38,4 & 30,7 & 30,8 & 28,4 \\
\hline Viagem corporativa & -- & 16,9 & 19,5 & 17,9 & 17,1 & 15,6 & 16,0 \\
\hline Agência de Viagens & 11,3 & -- & 8,5 & 8,6 & 13,6 & 12,2 & 14,5 \\
\hline Guias turísticos e impressos & -- & 8,4 & 7,5 & 5,8 & 6,5 & 7,3 & 6,2 \\
\hline Feiras, eventos e congressos & -- & -- & -- & 1,3 & 1,6 & 1,4 & 1,4 \\
\hline Folders e brochuras & -- & 1,1 & 0,4 & 0,5 & 0,4 & 0,3 & 0,4 \\
\hline Outros & 24,6 & 10,6 & 4,5 & 3,1 & 2,5 & 2,3 & 2,2 \\
\hline
\end{tabular}

Fonte: Ministério do Turismo (2012)

A utilização das fontes de informação para a organização de viagem confirma que Turismo e Comunicação formam um conjunto indissociável (Rushmann, 1999), já que as viagens turísticas se realizam, no mundo globalizado, em razão do acesso a informações transmitidas pelos 'mass midia'- meios de comunicação de massa tradicionais - o jornal, o rádio, a televisão, a revista -, e, a partir do final do século XX, por intermédio da 'mídia social'. O estudo do Ministério do Turismo corrobora a tese de Ruschmann e Quadro (2008) sobre o papel exercido pelos meios de comunicação na efetivação das viagens turísticas.

Estudo de Kerstetter e Cho (2004) encontrou que pessoas com maiores níveis de conhecimento anterior (experiência passada e perícia) tendem a usar menos e atribuir menor confiança à internet. Entretanto, a pesquisa do Ministério do Turismo mostrou que a internet é a principal fonte de informações na escolha do destino de uma viagem, já que a rede mundial ficou em primeiro lugar na pesquisa, com 30,9\% das respostas no ano de 2010. 
Da pesquisa 'Práticas de Comunicação Digital', elaborada para a ANJ, foram extraídas informações sobre as redes sociais baseadas na internet e disponibilizadas ao público pelos 80 jornais associados. O perfil da amostra incluiu cargo/função (editor-chefe, diretor de redação, editor executivo, chefe de redação, diretor de jornalismo, chefe de reportagem, editor, editorgeral, secretário de redação e outros) e tempo de atuação (mais de 10 anos, entre 6 e 10 anos, entre 2 e 5 anos, menos de 2 anos).

O Gráfico 1 apresenta alguns resultados, relativos ao uso das redes sociais por jornalistas, mostrando, por exemplo, o fato de que o YouTube/Vimeo (89\%), Facebook (80\%) e Twitter (80\%) são as redes sociais baseadas na internet mais utilizadas pelos profissionais de imprensa.

Gráfico 1 - Redes Sociais utilizadas por jornalistas

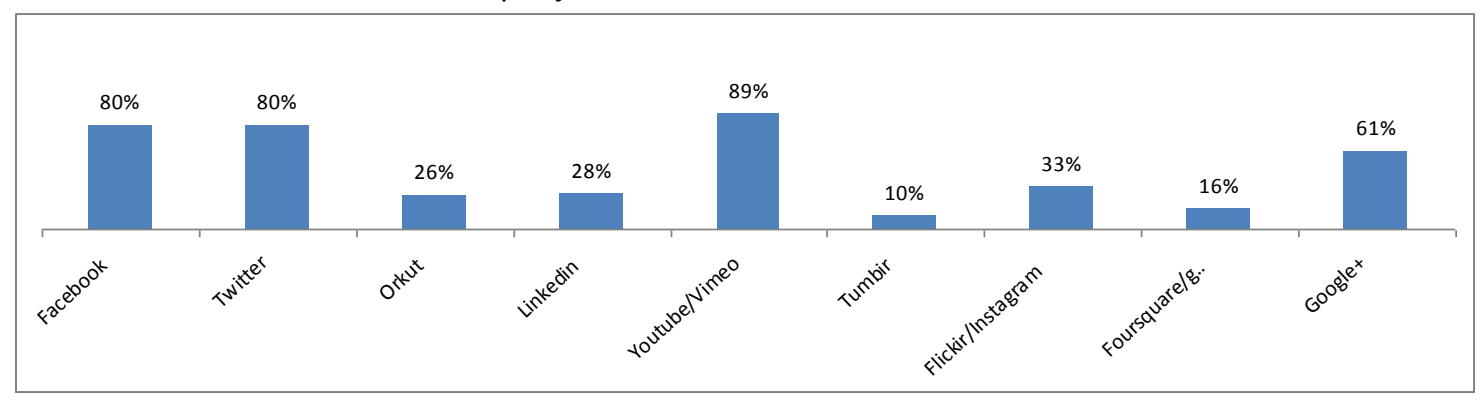

Fonte: ANJ (2012)

Já o Gráfico 2 assegura que as redes sociais mais utilizadas pelos jornalistas (Google +, YouTube/ Vimeo, Twitter e Facebook) são também aquelas que aliam perfil profissional e pessoal.

Gráfico 2 - Fins de utilização de Redes Sociais pelos jornalistas

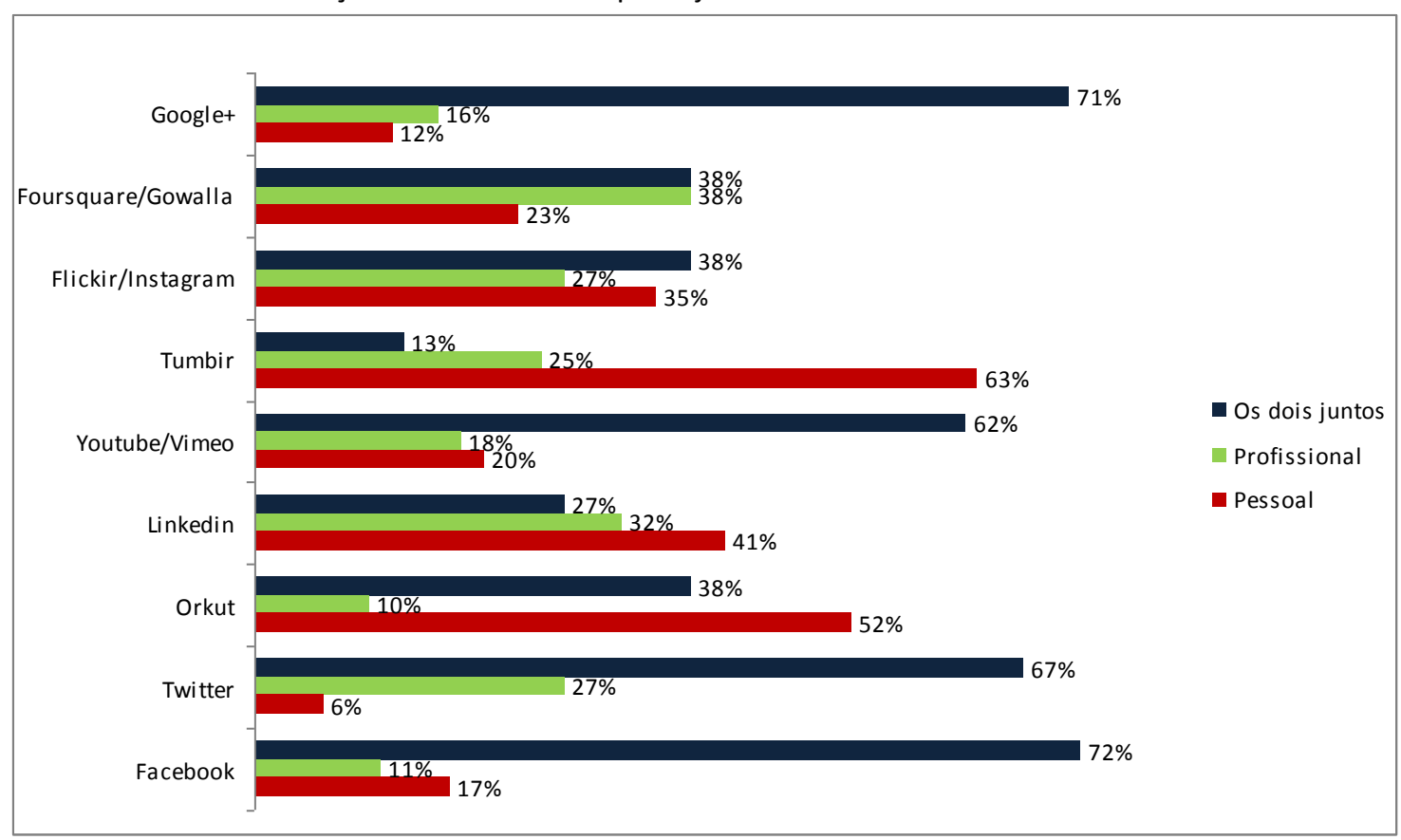

Fonte: ANJ (2012) 
O Instituto Verificador de Circulação (IVC) apresenta o descritivo das métricas verificadas na auditoria web no jornal ' $O$ Tempo', no ano de 2011, baseado em suas normas técnicas e seguindo a padronização internacional do IFABC, e que são as seguintes:

a) page impressions - arquivos enviados a um usuário, como resultado de uma solicitação de impressão recebida pelo servidor;

b) unique browser - métrica que não mede pessoas, mas os dispositivos pelos quais as pessoas interagem com os sites, ou seja, equipamentos a partir dos quais é feito acesso ao site;

c) visits - número de acessos ao site.

Os números certificados foram apurados através de comprovações consideradas necessárias pelos auditores do órgão, sendo que, com relação ao jornal 'O Tempo', o IVC apresentou o seguinte descritivo, relativamente ao ano de 2011 (Quadro 2).

Quadro 2 - Audiência web do Jornal 'O Tempo'

\begin{tabular}{|l|l|l|l|}
\hline Mês & Page impressions & Unique browsers & Visits \\
\hline Janeiro & 8.840 .613 & 570.653 & 1.264 .971 \\
\hline Fevereiro & 8.469 .389 & 526.758 & 1.209 .951 \\
\hline Março & 9.580 .917 & 556.680 & 1.309 .638 \\
\hline Abril & 9.126 .045 & 552.669 & 1.297 .569 \\
\hline Maio & 9.720 .694 & 611.716 & 1.429 .174 \\
\hline Junho & 9.358 .340 & 608.786 & 1.413 .900 \\
\hline Julho & 9.174 .479 & 579.927 & 1.373 .899 \\
\hline Agosto & 10.753 .615 & 697.308 & 1.659 .624 \\
\hline Setembro & 11.304 .106 & 665.134 & 1.632 .417 \\
\hline Outubro & 10.307 .437 & 633.103 & 1.536 .486 \\
\hline Novembro & 10.307 .625 & 664.243 & 1.561 .023 \\
\hline Dezembro & 10.714 .803 & 672.627 & 1.622 .341 \\
\hline
\end{tabular}

Fonte: Auditoria do Instituto Verificador de Circulação (IVC)

Em suma, as métricas verificadas na auditoria de 'O Tempo' demonstram que os page impressions, unique browsers e visits tiveram números crescentes ao longo dos meses, o que sugere a maior exposição da mensagem jornalística e aumento de audiência web. Dessa forma, a rede social baseada no portal 'O Tempo' pode ser considerada fonte de informação para públicos que variam de 8,8 milhões a 10,7 milhões de pessoas que acessam a internet.

A auditoria do IVC comprova a afirmação de Kliatchko (2002), segundo a qual as novas mídias são importantes para complementar os métodos de comunicação tradicionais como o jornal, a revista, televisão e o rádio, contribuindo, assim, para o estabelecimento de uma estratégia integrada, disponível em tempo real e acessível pelo público leitor através de diversas formas em todo o mundo globalizado.

A partir das entrevistas realizadas, pode-se identificar que as empresas jornalísticas 
editoras de cadernos de turismo se adaptam à mídia social, obtendo expressivas audiências online, o que reforça a estratégia integrada novas mídias-mídias tradicionais de Kliatchko (2002), como pode ser visto na fala de E1:

Os jornais acabaram se adaptando, entendendo que o consumidor de informação não é apenas um cliente, ele é também um parceiro que pode mostrar o que necessita e deseja ler. As pessoas sentem necessidades de se posicionar, isso acaba sendo um dever de cada cidadão. Qualquer informação divulgada online, imediatamente temos um retorno. Se precisamos saber como o trânsito flui por conta de uma greve, teremos informações de nossos leitores que estão em toda parte, o que é um retorno mais rápido do que se fosse dada pelos jornalistas da redação. Dentro do portal de "O Tempo", foi criado um ambiente de debate. Procuramos garantir esse espaço para o leitor! (E1).

Para Kliatchko (2002), a comunicação de massa, pelas novas tecnologias de informação e comunicação, reforça a utilização das mídias tradicionais, como o jornal, a revista, o rádio e a televisão, por meio de uma estratégia integrada e em tempo real e acessível de todas as partes do mundo. Isso é narrado com uma ênfase ainda maior por E2:

Após o advento das mídias sociais, os cadernos de turismo, em geral, atuam apenas como estimuladores de desejo do consumidor pelos destinos ali publicados. Os acessos que determinarão as compras, ou seja o momento da decisão se submete, quase que invariavelmente, a uma consulta em sites, blogs e redes sociais. Até o conhecimento não está livre dos modismos. Existe, hoje, de fato, uma tendência a fragmentar o conhecimento em especialidades, fruto de uma postura pragmática, que chega a excessos. Mas no caso do jornalismo de turismo, essa questão não chega a ser problemática, pois, no âmbito da imprensa, o turismo raramente é tratado como conhecimento. As matérias, reportagens, relatos etc se limitam à descrição, impressões e informações sobre acessos (E2).

O fato de que turismo e comunicação são indissociáveis, e que a necessidade do turista é o ponto inicial para estabelecer a necessária comunicação (Engel; Blackwell; Minard, 2000), é mencionado por E3, ao lembrar que as redes sociais utilizadas pelos cadernos de turismo ajudam o leitor na tomada de decisão para a escolha de um destino turístico nacional ou internacional:

As redes sociais aproximam e fidelizam o leitor do veículo e/ou do jornalista e, ao mesmo tempo, facilitam o acesso à informação. Mesmo que o veículo não possua um website ou blog que reproduza o seu conteúdo, ele é arquivado e pode ser pesquisado mesmo por aqueles que não acompanham essas redes sociais, uma vez que o conteúdo das mesmas é constantemente atualizado e indexado por sites de busca como Google, Bing, Yahoo etc., que podem ser acessados gratuitamente por qualquer pessoa (E 3).

Ainda para E3, as novas redes sociais podem ser apropriadas pelas empresas jornalísticas, de modo a diferenciar-se da concorrência:

As redes sociais são novos meios de comunicação, que como as demais exige linguagem, práticas e métricas específicas. Têm como principais diferenciais o baixíssimo investimento, a interatividade e a expansão geométrica. Se a empresa jornalística se 
dedicar a entender, conhecer a fundo e aproveitá-los, poderá não só desenvolver novos canais de comunicação que podem aproximá-la de seus diversos públicos, gerar leitura de seus veículos de comunicação, multiplicar o alcance e complementar o conteúdo desses outros veículo e desenvolver ações promocionais até chegar a desenvolver veículos de comunicação específicos para esses novos meios (E3).

O acesso às novas tecnologias de forma livre, igualitária e gratuita (Moore, 1999) é mencionado por E3, possibilitando que a disponibilidade da informação jornalística se universalize em um contexto de maior interação com o público leitor:

Os smartphones, tablets, netbooks, notebooks, PDAs e outros tipos de dispositivos móveis já são muito importantes para o acesso a determinados perfis de público. A tendência é que passem a ocupar cada vez mais espaço, substituindo os já quase arcaicos desktops e permitindo o acesso à informação a qualquer hora, de qualquer lugar, cidade ou país. Alguns deles ainda exigem interfaces específicas para melhor aproveitamento, mas isso em breve será um obstáculo irrelevante. Talvez as transformações mais importantes sejam a democratização do acesso à informação decorrente da universalização do acesso a telefones celulares (o termo smartphone tende a ser abandonado). Hoje, a maioria dos celulares oferecidos já é 'inteligente'; a possibilidade da publicação de notícias "ao vivo", incorporando texto, imagem, vídeo e áudio com investimento mínimo; a universalização do acesso à informação e a instantaneidade da interação com o público leitor, que pode sugerir pautas e ajudar a criar e modificar matérias (E3).

Assim, os resultados sugerem que na perspectiva do jornal estudado, a necessidade de investimento em redes sociais é necessária para o acompanhamento das alterações sociais que os avanços tecnológicos vêm trazendo ao setor jornalístico. Por outro lado, essa facilidade de informação reforça a existência de cadernos especializados, como o de turismo, uma vez que a internet tem se destacado como a principal fonte de informação para viajantes em potencial.

Cabe ainda, uma reflexão sobre até que ponto as redes sociais são aliados da promoção de destinos turísticos, uma vez que a interação entre empresas e viajantes propicia a existência de comentários tanto positivos quanto negativos dos destinos destacados na internet. Nesse sentido, Cho (2009) afirma que pessoas que tiveram experiências positivas podem incentivar que outros visitem o local; já experiências negativas podem degradar a percepção do turista sobre o local e induzir que outros não viajem até lá. Portanto, não só a fonte de informação deve ser base de estudos turísticos, mas a experiência do visitante após a experiência no destino.

\section{CONSIDERAÇÕES FINAIS}

A pesquisa atingiu o objetivo geral, ao investigar o uso das redes sociais baseadas na internet como fonte de informação para o conhecimento de destinos turísticos.

As métricas do IVC, relativas ao portal 'O Tempo' indicam a importância da internet como fonte de informação geral, sendo que o uso desse portal foi feito por públicos que variam, mensalmente, de 8,8 milhões a 10,7 milhões de internautas para page impressions, 570.000 a 672.000 , no caso de unique browsers e 1,2 milhão a 1,6 milhão, relativamente a visits, no período de janeiro a 
dezembro de 201.

A Pesquisa 'Práticas de Comunicação Digital', da ANJ, mostra que 100\% dos jornalistas que utilizam as redes sociais, em seu trabalho diário nas redações, acompanham notícias publicadas por outras empresas jornalísticas, $93 \%$ buscam novos fontes para o trabalho de apuração jornalística e, apenas $10 \%$, comentam a cobertura jornalística de outras empresas de informação que são concorrentes.

Os dados coletados nas entrevistas permitiram conhecer alguns pontos relevantes com relação à utilização das redes sociais como disseminadoras da informação jornalística especializada em turismo: o fato da mídia social ser caracterizada como a maior revolução que a civilização assistiu no modo de processar, transmitir informações e de relacionar pessoas e grupos; a ampliação exponencial das possibilidades de contatos diretos com públicos diversos nos ambientes das redes; o fenômeno das redes sociais aproximar e fidelizar o leitor dos cadernos especializados em turismo e, ao mesmo tempo, facilitar o acesso à informação jornalística disponibilizada nas redes sociais baseadas na internet; a possibilidade das redes sociais veicularem notícias 'ao vivo', incorporando texto, imagem, vídeo e áudio, o que possibilita a universalização do acesso à informação e a instantaneidade da interação com o público leitor.

Assim, os resultados da pesquisa indicam que a utilização das redes sociais é crescente na empresa estudada, podendo se tornar uma vantagem competitiva por parte das empresas jornalísticas na difusão do conhecimento, inclusive o especializado em turismo, dada a sua ubiquidade e possibilidade de aproximação com o público alvo. Contudo, são necessários mais investigações sobre o tema, de forma a aprofundar os desdobramentos da utilização da internet e redes sociais como fonte de informação de viagem para destinos turísticos. Outros estudos podem avaliar a qualidade percebida das informações repassadas no ponto de vista dos leitores e estudar o desdobramento do comportamento dos mesmos (por exemplo, verificar aqueles que divulgaram a matéria em rede social própria, curtiram, compartilharam, comentaram e até se a matéria impulsionou um comportamento de consumo).

Algumas limitações desta pesquisa não podem deixar de ser mencionadas. Por tratar-se de um estudo de caso, não é possível fazer generalizações. Assim, este estudo poderia ser realizado em outras empresas jornalísticas especializadas em turismo, buscando ampliar o seu escopo. Além disso, a pesquisa qualitativa pode ter incorporado vieses não intencionais às análises durante as entrevistas e análise dos dados. Por fim, sendo um tema recente e em constante mudança, este trabalho também esbarrou em limitações teóricas sobre as redes sociais quando relacionadas ao turismo, que também demanda investigações longitudinais e desenvolvimento de teorias.

\section{REFERÊNCIAS}

Afonso, Juliana (2010), Entrevista com Berthier Ribeiro Neto. Diversa. Belo Horizonte: ano 9, n.18, ago., p.6.

Associação Nacional De Jornais-Anj (2011). Pesquisa "Práticas de Comunicação Digital". 21/9 a 10/10/11. Disponível em , <http:// www.anj.org.br> . Acesso em: 17 jan. 2012. 
Bardin, Laurence(2008). Análise de Conteúdo. 5 ed. Lisboa: Edições 70.

Buhalis, D. (1998).Strategic use of information technologies in the tourism industry. Tourism Management, v. 19, n.5, p.409-421.

Buhalis, D.; Law, R.(2008). Progress in information technology and tourism management: 20 years on and 10 years after the Internet-The state of eTourism research. Tourism Management, n.29, p.609-623.

Cho, V. (2008) Linking Tourism Attractiveness and tourist intention. Tourism and Hospitality Research, v. 8, n.3, p.220-224.

Engel, J.; Blackwell, R; Minard, P. W. (2000) Comportamento do consumidor. Rio de Janeiro: LTC.

Erbolato, Mário L. (1981) Jornalismo especializado: emissão de textos no jornalismo impresso. São Paulo: Atlas. 158p.

Ferrari, Cynthia Menezes Mello (2002). O relacionamento da mídia impressa e o turismo. Dissertação (Mestrado) - Universidade de São Paulo, Escola de Comunicação e Artes, São Paulo.

Folha De S.Paulo (2011). Mais da metade da população prevê jornal impresso em 2050. Caderno de Economia. $23 \mathrm{dez}$.

IBOPE-Instituto Brasileiro de Opinião Pública e Estatística (2011b). 73,9 milhões de pessoas têm acesso à internet no Brasil. 18 mar. Disponível em:

<http://www.ibope.com.br/calandraWeb/servlet/CalandraRedirect?temp=6\&proj=PortallBOPE\&pub=T\&no me=home_materia\&db=caldb\&docid=EA0526673CE1740D832578570054B23B $>$. Acesso em: 19 mar. 2014.

Instituto Verificador De Circulação-IVC . Auditoria: Métricas certificadas pelo IVC: audiência web do Tempo Online.

Kliatchko, J. (2002). Understanding integrated marketing communications. Philippines: Inkwell Publishing.

Lévy, Pierre. Pela ciberdemocracia (1999). In: Moraes, Dênis De (Org.). Por uma outra comunicação. São Paulo: Editora 34.

Lopes, Sonia Aguiar (2007). Redes sociais em tempos de Internet. Disponível em

<http://www.ibase.br/modules.php?name=Conteudo\&pid=1726>. Acesso em: 22 maio 2007.

Mathieson, A.; Wall, G. (1982). Tourism: economic, physical and social impacts, Harlow: Longman.

Mattila, A. S. (2004) Consumer behavior research in hospitality and tourism journals. International Journal of Hospitality Management, v.23, p. 449-457.

Miguéns, J.; Baggio, R.; Costa, C. (2008).Social media and Tourism Destinations: TripAdvisor Case Study. In: ADVANCES IN TOURISM RESEARCH, 2008, Aveiro, Portugal. Anais...Aveiro. p.1-6.

Ministério Do Turismo (2012). Estudo da Demanda Turística Internacional - 2004-2010. Disponível em <htt://www.turismo.gov.br. Acesso em 17 jan.2012. 
Moutinho, L. (1987). Consumer behaviour in tourism. European Journal of Marketing. 21. n. 10, 1-44.

Pan, B.; Fesenmaier, D. R.(2006). Online information search: Vacation planning process. Annals of Tourism Research, v. 33, n. 3, p. 809-832.

Ronsini, Veneza Mayora (1993). Cotidiano rural e recepção da televisão : o caso Três Barras. São Paulo, 1993. 152 p. Dissertação (Mestrado em Comunicação) - Escola de Comunicação e Artes, Universidade de São Paulo (USP).

Ruschmann, D. M.; Quadro, L. Formação Baseada em Competências no Turismo: Análise do Modelo Proposto pelo Instituto de Hospitalidade. In: V SEMINÁRIO DE PESQUISA EM TURISMO DO MERCOSUL. 2008

Rushmann, Doris Van De Meene(1990). Marketing Turístico: um enfoque promocional. Campinas, SP: Papirus.

Ruzic, D.; Bilos, A. (2010). Social Media in Destination Marketing. Tourism \& Hospitality Management, Conference Proceedings, p. 178-190, 2010.

Swarbrooke, J.; Horner, S. (2002). Comportamento do consumidor de turismo. São Paulo: Aleph. 405 p.

Tierney, P. (2000) Internet-based evaluation of tourism Web site effectiveness: methodological issues and survey results. Journal of Travel Research, n. 39, n., p 212-219.

Tótoli, F. N.; Rossi, G. B. (2012)Mídias Sociais promovendo lealdade: um estudo empírico sobre o twitter. In: ENCONTRO DE MARKETING DA ANPAD, 5., 2012. Anais...Curitiba: ANPAD.

Tuominen, P. The Influence of TripAdvisor Consumer-Generated Travel Reviews on Hotel Performance (2011). Annual Frontiers in Service Conference, p.1-11.

Tuten, T. L.; Solomon, M. (2013) Social Media Marketing. New Jersey: Pearson.

Vergara, S,.C . (2003) Projetos e relatórios de pesquisa em administração. 4. ed. São Paulo: Atlas. 90 p.

Xiang, Z.; Gretzel, U. (2010). Role of social media in online travel information search. Tourism Management, n. 31, p.179-188.

Ye, Q.; Law, R.; Gu, B. (2009). The impact of online user reviews on hotel room sales. International Journal of Hospitality Management, n. 28, p.180-182.

YIN, Robert K. Estudo de caso: planejamento e métodos. 3 ed. Porto Alegre: Bookman, 2005. 212 p.

Zauner, A.; Koller, M.; Fink, M. (2012) Sponsoring, Brand Value and Social Media. RAE, São Paulo, v. 52,n. 6, p. 681-691, nov. /dez.

Artigo recebido em: 14/05/2014.

Artigo aprovado em: 22/11/2014. 